\section{Hematopoietic recovery and immune reconstitution after axicabtagene ciloleucel in patients with large B-cell lymphoma}

\author{
Paolo Strati, ${ }^{1}$ Ankur Varma, ${ }^{2,4}$ Sherry Adkins, ${ }^{1}$ Loretta J. Nastoupil, ${ }^{1}$ Jason R. \\ Westin, ${ }^{1}$ Fredrick B Hagemeister, ${ }^{1}$ Nathan H Fowler, ${ }^{1}$ Hun J. Lee,${ }^{1}$ Luis E. \\ Fayad, ${ }^{1}$ Felipe Samaniego, ${ }^{1}$ Sairah Ahmed, ${ }^{1}$ Yiming Chen, ${ }^{1}$ Sandra Horowitz, ${ }^{1}$ \\ Sara Arafat, ${ }^{1}$ Swapna Johncy, ${ }_{1}^{1}$ Partow Kebriaei, ${ }^{2}$ Victor Eduardo Mulanovich, ${ }^{3}$ \\ Ella Ariza Heredia ${ }^{3}$ and Sattva S. Neelapu ${ }^{1}$
}

${ }^{1}$ Department of Lymphoma and Myeloma, The University of Texas MD Anderson Cancer Center, Houston, TX; ${ }^{2}$ Department of Stem Cell Transplantation,The University of Texas MD Anderson Cancer Center, Houston, TX; ${ }^{3}$ Department of Infectious Disease, The University of Texas MD Anderson Cancer Center, Houston, TX, and ${ }^{4}$ Division of Hematology, Oncology and Cellular Therapy, Rush University, Chicago, IL, USA

\section{ABSTRACT}

C himeric antigen receptor (CAR) T-cell therapy targeting CD19 may be associated with long-term adverse effects such as cytopenia and immune deficiency. In order to characterize these late events, we analyzed 31 patients with relapsed or refractory large B-cell lymphoma treated with axicabtagene ciloleucel at our institution on two clinical trials, ZUMA-1 (clinicaltrials gov. Identifier: NCT02348216) and ZUMA-9 (clinicaltrials gov. Identifier: NCT03153462). Complete blood counts, lymphocyte subsets, and immunoglobulin levels were measured serially until month 24 or progression. Fifteen (48\%) patients had grade 3-4 cytopenia, including anemia (five, 16\%), neutropenia (nine, 29\%), or thrombocytopenia $(13,42 \%)$ at day 30 . Cytopenia at day 30 was not significantly associated with later diagnosis of myelodysplasia. Among patients with ongoing remission, grade 3-4 cytopenia was observed in one of nine $(11 \%)$ at 2 years. While peripheral $\mathrm{CD}^{+} \mathrm{T}$ cells recovered early, CD4+ ${ }^{+}$-cell recovery was delayed with a count of $<200 / \mu \mathrm{L}$ in three of nine $(33 \%)$ patients at 1 year and two of seven $(29 \%)$ at 2 years. Immunoglobulin $\mathrm{G}$ levels normalized in five of nine $(56 \%)$ patients at 2 years. Thirteen (42\%) patients developed grade 3-4 infectious complications, including herpes zoster and Pneumocystis jiroveci pneumonia. These results suggest the need for prolonged monitoring and prophylaxis against opportunistic infections in these patients, to improve the longterm safety of axicabtagene ciloleucel therapy.

\section{Introduction}

Chimeric antigen receptor (CAR) T-cell therapies targeting CD19, such as axicabtagene ciloleucel (axi-cel), have significantly improved the outcome of patients with refractory large B-cell lymphoma (LBCL). ${ }^{1-4}$ While acute toxicities, such as cytokine release syndrome (CRS) and neurotoxicity, have been well reported, late adverse effects, such as cytopenia and immune deficiency, have not been well characterized. . $^{5-7}$

Cytopenias lasting beyond day 30 post infusion have been observed with most CAR T-cell products, suggesting a class effect rather than a complication of conditioning chemotherapy. ${ }^{1,3,8-10}$ In addition, prolonged B-cell aplasia is a known on-target off-tumor effect of anti-CD19 CAR T-cell therapies. ${ }^{2}$ It is unclear at this time how long it takes for cytopenias to resolve and at what point these patients should be worked up for myelodysplastic syndrome (MDS). It is also unknown what the timing of T-cell immune reconstitution is after axi-cel therapy and whether these patients are at short or long-term risk of infectious complications.
Haematologica 2021

Volume 106(10):2667-2672

\section{Correspondence:}

SATTVA S. NEELAPU

sneelapu@mdanderson.org

Received: March 30, 2020.

Accepted: July 14, 2020.

Pre-published: July 30, 2020.

https://doi.org/10.3324/haematol.2020.254045

(C)2021 Ferrata Storti Foundation

Material published in Haematologica is covered by copyright. All rights are reserved to the Ferrata Storti Foundation. Use of published material is allowed under the following terms and conditions:

https://creativecommons.org/licenses/by-nc/4.0/legalcode. Copies of published material are allowed for personal or internal use. Sharing published material for non-commercial purposes is subject to the following conditions:

https://creativecommons.org/licenses/by-nc/4.0/legalcode, sect. 3. Reproducing and sharing published material for commercial purposes is not allowed without permission in writing from the publisher. 


\section{Methods}

\section{Patient selection and evaluation}

This is a post-hoc analysis of patients with refractory LBCL treated with axi-cel on the pivotal ZUMA-1 study (clinicaltrials gov. Identfier: NCT02348216; n=24) or ZUMA-9 (clinicaltrials gov. Identfier: NCT03153462; n=7); the latter was an expanded access trial for patients not eligible for ZUMA-1 study (cohort 1) or whose commercial product was out-of-specification (OOS) (cohort 2), and two patients from cohort 2 were included in this analysis. Patients were treated at MD Anderson Cancer Center between 01/2015 and 03/2018 (data cut-off: 12/19/2018). The studies were approved by the Institutional Review Board and conducted in accordance with institutional guidelines and the principles of the Declaration of Helsinki.

Conditioning chemotherapy and axi-cel infusion were administered as previously described. ${ }^{1,2}$ Clinical and laboratory features were collected prospectively in all patients who had a complete blood count (CBC) performed 30 days (+/- 5 days) after axi-cel infusion. Pre-conditioning laboratory values were available for $\mathrm{CBC}$ but not for lymphocyte subsets. Patients who received treatment and/or died for progression before day 30 were excluded. Infectious complications and diagnosis of MDS were reported from axi-cel infusion until last follow-up, progression, subsequent therapy or death. CRS and neurotoxicity were prospectively grad- ed according to Lee 2014 criteria and CTCTAE v4.03, respectively. ${ }^{11}$ Response status was determined by 2007 revised response criteria for malignant lymphoma. ${ }^{12}$

\section{Hematopoietic recovery and immune reconstitution assessment}

In order to assess blood count and immune recovery, we performed $\mathrm{CBC}$, lymphocyte subsets analysis by flow cytometry, and immunoglobulin G (IgG) levels at months 1, 3, 6, 9, 12, 15, 18 and 24 , or until disease progression.

\section{Statistical analysis}

Categorical and continuous variables were evaluated using Chi square $\left(\chi^{2}\right)$ or Fisher exact tests, or the Mann-Whitney test, as appropriate, to describe differences in baseline characteristics, response and toxicity between patients groups. Association between continuous variables were assessed using the bivariate Pearson correlation. A $P$-value of $\leq 0.05$ (two-tailed) was considered statistically significant (IBM SPSS 23).

\section{Results}

Patient baseline characteristics

Grade 3-4 cytopenias were observed in 15 (48\%) of 31

Table 1. Baseline (day -5) characteristics by grade 3-4 cytopenia at day 30 after axi-cel infusion.

\begin{tabular}{|c|c|c|c|c|}
\hline & $\begin{array}{l}\text { Total } \\
(N=31) \\
N(\%)\end{array}$ & $\begin{array}{c}\text { Grade } 3-4 \text { cytopenia } \\
\text { at } 30 \text { days }(N=15) \\
N(\%)\end{array}$ & $\begin{array}{c}\text { No Grade } 3-4 \text { cytopenia } \\
\text { at } 30 \text { days (N=16) } \\
N(\%)\end{array}$ & P-value \\
\hline $\begin{array}{l}\text { DLBCL } \\
\text { PMBCL } \\
\text { TFL }\end{array}$ & $\begin{array}{c}21(68) \\
6(19) \\
4(13)\end{array}$ & $\begin{array}{c}12(80) \\
2(13) \\
1(7)\end{array}$ & $\begin{array}{l}9(56) \\
4(25) \\
3(19)\end{array}$ & 0.35 \\
\hline Age in years, median (range) & $52[23-76]$ & $58[23-76]$ & $51[28-75]$ & 0.86 \\
\hline $\begin{array}{l}\text { Male } \\
\text { Female }\end{array}$ & $\begin{array}{c}23(74) \\
8(26)\end{array}$ & $\begin{array}{l}9(60) \\
6(40)\end{array}$ & $\begin{array}{l}14(88) \\
2(12)\end{array}$ & 0.11 \\
\hline $\begin{array}{r}\text { ECOG } 0 \\
1 \\
\end{array}$ & $\begin{array}{l}19(61) \\
12(39)\end{array}$ & $\begin{array}{l}6(40) \\
9(60)\end{array}$ & $\begin{array}{l}13(81) \\
3(19)\end{array}$ & 0.03 \\
\hline $\begin{array}{l}\text { Ann Arbor Stage I-II } \\
\text { III-IV }\end{array}$ & $\begin{array}{l}7(23) \\
24(77)\end{array}$ & $\begin{array}{l}2(13) \\
13(87)\end{array}$ & $\begin{array}{c}5(48) \\
11(52)\end{array}$ & 0.39 \\
\hline $\begin{array}{l}\text { No BM involvement } \\
\text { BM involvement }\end{array}$ & $\begin{array}{c}28(90) \\
3(10)\end{array}$ & $\begin{array}{l}13(87) \\
2(13)\end{array}$ & $\begin{array}{c}15(94) \\
1(6)\end{array}$ & 0.60 \\
\hline $\begin{array}{r}\text { IPI score } 0-2 \\
3-4\end{array}$ & $\begin{array}{l}18(58) \\
13(42)\end{array}$ & $\begin{array}{l}6(40) \\
9(60)\end{array}$ & $\begin{array}{c}12(75) \\
4(25)\end{array}$ & 0.07 \\
\hline Previous therapies (n) & $3[1-11]$ & $4[2-8]$ & $3[1-11]$ & 0.05 \\
\hline$>3$ previous therapies & $14(45)$ & $10(67)$ & $4(25)$ & 0.03 \\
\hline Refractory disease & $30(97)$ & $15(100)$ & $15(94)$ & 1 \\
\hline Previous ASCT & $11(35)$ & $8(53)$ & $3(19)$ & 0.07 \\
\hline Cytopenia at day -5 & $4(13)$ & $3(20)$ & $1(6)$ & 0.33 \\
\hline ANC $\left(10^{9} / \mathrm{L}\right)$, median (range) & $4[0.8-24.8]$ & $4[1.1-24.9]$ & $3.8[0.8-12]$ & 0.86 \\
\hline AMC $\left(10^{9} / \mathrm{L}\right)$, median (range) & $0.5[0.1-1.6]$ & $0.5[0.1-1.2]$ & $0.5[0.3-1.6]$ & 0.72 \\
\hline $\operatorname{ALC}\left(10^{9} / \mathrm{L}\right)$, median (range) & $0.5[0.2-3.6]$ & $0.4[0.2-3.6]$ & $0.7[0.2-1.6]$ & 0.007 \\
\hline Hemoglobin (g/dL), median (range) & $10.9[7.4-14.2]$ & $10.7[7.4-12.6]$ & $11.3[9.3-14.2]$ & 0.10 \\
\hline PLT count $\left(10^{9} / \mathrm{L}\right)$, median (range) & $157[31-409]$ & $105[31-356]$ & $184[67-409]$ & 0.21 \\
\hline Ferritin (ng/mL), median (range) & 747 [209-9388] & 2205 [230-9388] & $450[209-1554]$ & 0.08 \\
\hline CRP (mg/L), median (range) & $51[2.7-352]$ & $62.3[2.7-352]$ & $39.3[3-268]$ & 1 \\
\hline LDH (U/L), median (range) & $703[362-3426]$ & $703[362-3426]$ & 681 [369-1667] & 1 \\
\hline
\end{tabular}

DLBCL: diffuse large B-cell lymphoma; PMBCL: primary mediastinal B-cell lymphoma; TFL: transformed follicular lymphoma; BM: bone marrow; IPI: international prognostic index; n: number; ASCT: autologous stem cell transplant; ANC: absolute neutrophil count; AMC: absolute monocyte count; ALC: absolute lymphocyte count; PLT: platelet; CRP: Creactive protein; $\mathrm{LDH}$ : lactate dehydrogenase. 
patients at day 30 (D30) after axi-cel infusion, and included neutropenia in nine $(29 \%)$ patients, anemia in five $(16 \%)$ and thrombocytopenia in $13(42 \%)$ patients.

On univariate analysis, baseline characteristics significantly associated with D30 grade 3-4 cytopenia were the Eastern Cooperative Oncology Group (ECOG) performance status $1(P=0.03),>3$ prior therapies $(P=0.03)$, and low absolute lymphocyte count (ALC) $(P=0.007)$ (Table 1$)$.

\section{Hematopoietic recovery and immune reconstitution}

Fifteen patients included in this analysis had ongoing remission at 1 year and 10 at 2 years (one did not have evaluable $\mathrm{CBC}$ ). While these included both patients from ZUMA-1 and ZUMA-9, the two patients who received OOS product in cohort 2 of ZUMA-9 progressed before year 1 assessment. Among patients with ongoing remission, persistent grade 3-4 cytopenias was present in four of $15(27 \%)$ patients at 1 year and in one of nine (11\%) patients at 2 years (Figure 1A to C). Among these patients, samples for flow cytometry assessment were available in nine patients at 1 year, and seven patients at 2 years. While recovery of CD8 $8^{+} \mathrm{T}$ cells (median 597 cells/ $\mu \mathrm{L}$; range, 1431,492 cells $/ \mu \mathrm{L}$ ) and $\mathrm{CD} 56^{+}$natural killer (NK) cells (median 118 cells/ $\mu \mathrm{L}$; range, 38-236 cells/ $\mu \mathrm{L}$ ) occurred in nine of nine $(100 \%)$ patients by 1 year, reconstitution of $\mathrm{CD}^{+} \mathrm{T}$ cells was delayed, with normalization in six of nine $(67 \%)$ patients at 1 year (median 225 cells $/ \mu \mathrm{L}$; range, 108-593 cells $/ \mu \mathrm{L}$ ) and five of seven $(71 \%)$ patients assessed at 2 years (median 263 cells/ $\mu \mathrm{L}$, range 83-1,166 cells/ $\mu \mathrm{L}$ ); of interest, the age of patients who did not experience $\mathrm{CD} 4^{+} \mathrm{T}$ cell normalization at 1 and 2 years ranged from 40 to 67 years. IgG levels were normal in seven of thirteen $(54 \%)$ patients at 1 year (median $646 \mathrm{mg} / \mathrm{dL}$; range, 200-1,299 $\mathrm{mg} / \mathrm{dL}$ ) and five of nine (56\%) patients assessed at 2 years (median $552 \mathrm{mg} / \mathrm{dL}$; range, $366-1,147 \mathrm{mg} / \mathrm{dL}$ ) (Figure 1D to $\mathrm{H})$. When limiting the analysis to patients who did not receive intravenous IgG (IVIG) support, four of four had normalization of IgG levels at 1 year. Interestingly, a positive and significant association was observed between platelet count and CD56 cell count in ten patients with available samples for flow cytometry assessment $(\mathrm{r}=+0.64$, $P<0.001$ ) (Figure 1I).

\section{Risk of myelodysplastic syndrome}

When comparing the 15 patients with grade 3-4 D30 cytopenia to the 16 patients without grade 3-4 D30 cytopenia, the former received significantly higher number of platelet transfusions (11 of 15 [73\%] vs. four of 16 [25\%], $P=0.01$ ), but there was no significant difference in red blood cell transfusions (13 of 15 [87\%] vs. ten of $16[63 \%]$,
A

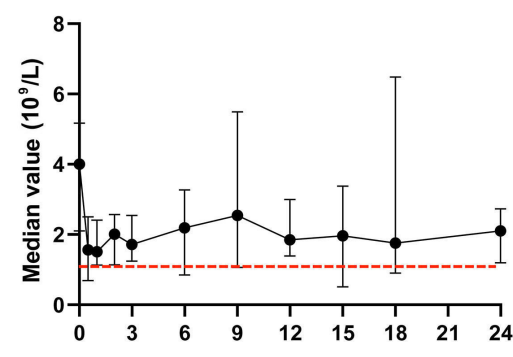

D

Absolute Lymphocyte Count
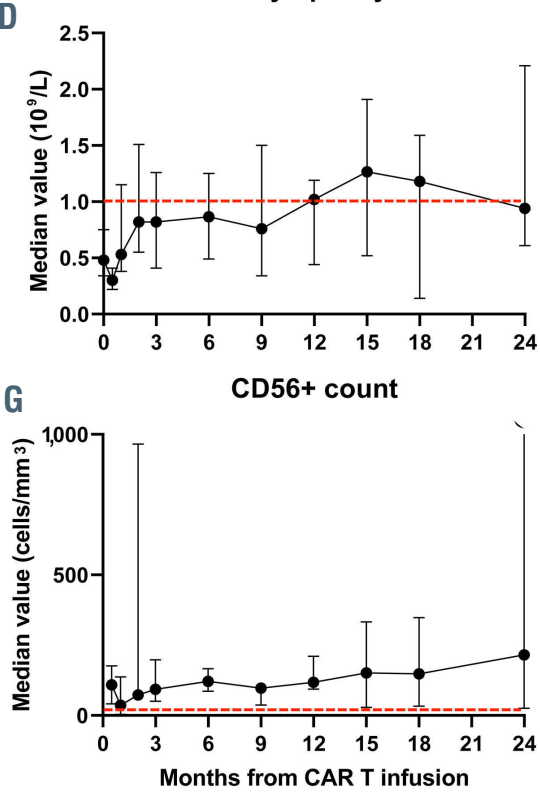

B
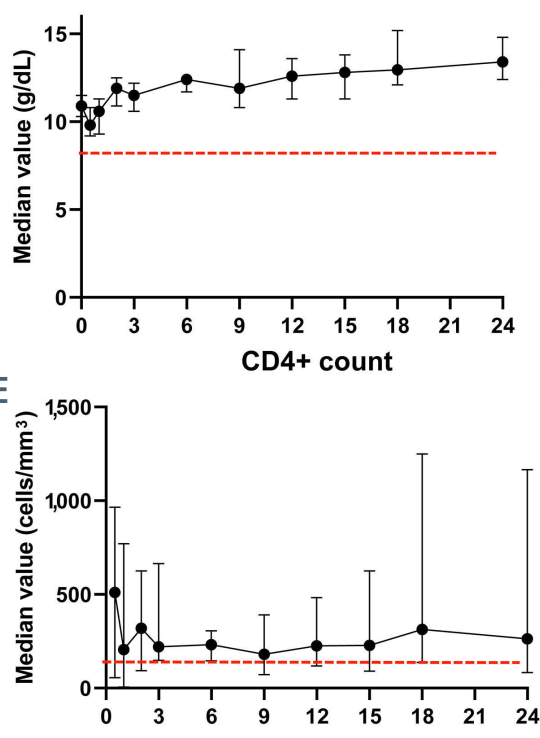

H

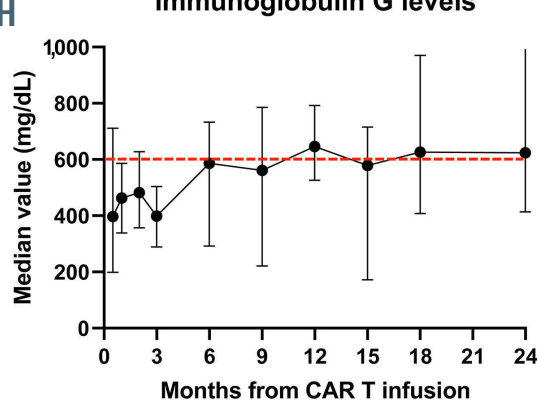

C

Platelet count
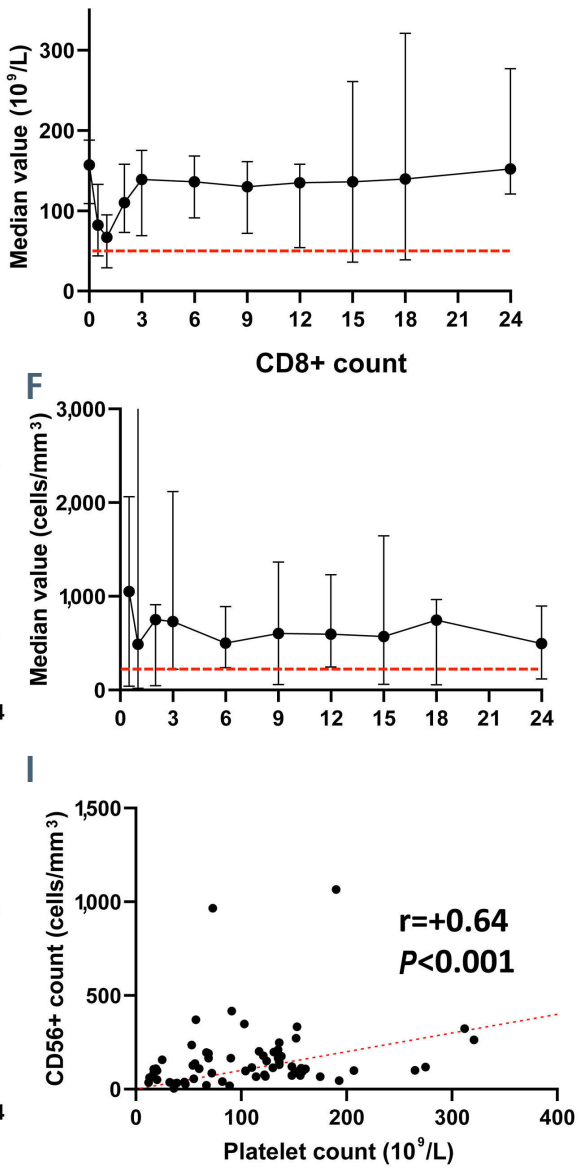

Figure 1. Trends in hematopoietic and immune reconstitution after axi-cel therapy in patients with relapsed or refractory large B-cell lymphoma. (A to C) Hematopoietic recovery (absolute neutrophil count, hemoglobin and platelet count. (D to H) Reconstitution of absolute lymphocyte count, CD4 $4^{+}, \mathrm{CD} 8^{+}$, CD56 ${ }^{+}$and immunoglobulin G up to 24 months after CART infusion. (I) Correlation between CD56 ${ }^{+}$cell immune reconstitution and platelet recovery. Red dotted line indicates lower limit of normal. 
$P=0.22)$. Four cases of $M D S$ were diagnosed, after a median of 13.5 months (range, 4-26 months) from axi-cel infusion, all attributed to previous chemotherapies: median number of previous systemic therapies in these four patients was five (range, 4-7), including autologous stem cell transplant in one patient. No significant difference in the incidence of MDS was observed between patients with and without grade 3-4 D30 cytopenia (three of 15 [20\%] vs. one of 16 [6\%], $P=0.33)$.

\section{Infectious complications}

All 31 patients received granulocyte colony stimulating factor (GCSF) support for neutropenia; 13 (42\%) received prophylactic IVIG and four (13\%) therapeutic IVIG; two (6\%) patients received antibacterial prophylaxis, 13 (42\%) Pneumocystis jiroveci pneumonia (PJP) prophylaxis, and 22 $(71 \%)$ antiviral prophylaxis, while no patient received antifungal prophylaxis. Overall, among patients with ongoing response, $24(77 \%)$ developed infectious complications with grade $\geq 3$ in 13 (42\%) (Figure 2). There was a trend for association between grade 3-4 D30 cytopenia and grade $\geq 3$ infectious complications (nine of 15 [60\%] vs. four of 16 [25\%], $P=0.07$ ), which was statistically significant when limiting the analysis to grade 3-4 D30 lymphopenia (nine of 14 [64\%] vs. four of 17 [24\%], $P=0.03$ ). Due to small sample size, the association between D30 CD4 count and infections could not be assessed. Among all 31 patients, 71 infectious events of any grade were reported, with no isolated organism in $40(56 \%)$ cases (Table 2). For these 71 infectious events, the most common etiology was viral (17 of 71 $[24 \%])$, followed by bacterial (ten of $71[14 \%]$ ) and fungal (four of $71[6 \%]$ ), whereas in the remaining cases an organism could not be isolated. Among viral infections, herpes zoster skin infection was the most common event, reported in five patients $(16 \%)$, none of whom were on antiviral prophylaxis. Median time from axi-cel infusion to onset of herpes zoster infection was 79 days (range, 49-723 days), and all cases resolved with valacyclovir therapy. One patient who was not on prophylaxis developed PJP 18 days after axi-cel infusion, and was successfully treated with sulfamethoxazole-trimethoprim.

\section{Toxicity and efficacy}

Among all 31 patients, 30 (97\%) patients developed CRS of any grade, grade $3-4$ in three $(10 \%)$, and $20(65 \%)$ patients developed neurotoxicity of any grade, grade 3-4 in $15(48 \%)$. No significant difference in incidence of grade 3-

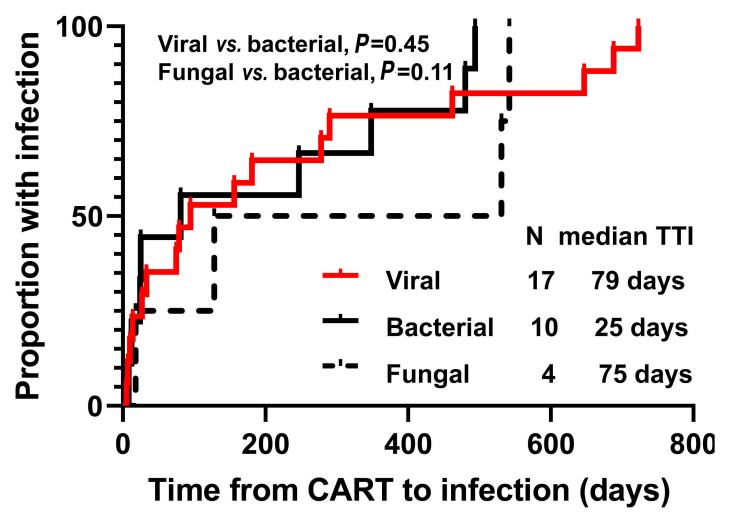

Figure 2. Median time to infection (TTI).
4 CRS $(13 \%$ vs. $6 \%, P=0.60)$ and in incidence of grade $3-4$ neurotoxicity (53\% vs. $44 \%, P=0.72$ ) was observed when comparing patients who developed D30 grade 3-4 cytopenia to those who did not.

In order to manage either CRS or neurotoxicity, 12 (39\%) patients required corticosteroids, and $21(68 \%)$ required tocilizumab. No difference in use of corticosteroids $(53 \%$ vs. $25 \%, P=0.15)$ or use of tocilizumab $(73 \%$ vs. $63 \%$, $P=0.70)$ was observed when comparing patients who developed D30 grade 3-4 cytopenia to those who did not.

Overall, $26(84 \%)$ patients achieved a response, and 19 (61\%) a complete response (CR). No statistically significant difference in overall response rate $(87 \%$ vs. $81 \%, P=1)$ or CR rate $(60 \%$ vs. $63 \%, P=1)$ was observed when comparing patients with D30 G3-4 cytopenia to those without. No statistically significant difference in median baseline ALC was observed when comparing patients who achieved a response to those who did not $\left(0.52 \times 10^{9} / \mathrm{L}\right.$ vs. $0.34 \times 10^{9} / \mathrm{L}$; $P=0.37$ ), or patients who achieved a CR to those who did not $\left(0.55 \times 10^{9} / \mathrm{L}\right.$ vs. $\left.0.39 \times 10^{9} / \mathrm{L} ; P=0.34\right)$.

\section{Discussion}

In summary, our results indicate that grade 3-4 cytopenia beyond D30 occurs after CAR T-cell therapy in a subset of patients. While cytopenias resolve in most patients, it can persist in one third of evaluable patients at 1 year, highlighting the importance of long-term monitoring.

The comparable incidence between our study and other reports suggests that the MDS was most likely due to prior therapies. ${ }^{13,14}$ Unfortunately, myeloid driver mutations were not tested in these patients before lymphodepleting chemotherapy, to further corroborate this hypothesis. While previous chemotherapies (and subsequent marrow reserve) and conditioning therapy may contribute to the prolonged myelosuppression, ${ }^{15,16}$ the observation of severe cytopenias in patients who have not received it suggests the intriguing hypothesis that they may instead signify intrabone marrow CAR T-cell activity. ${ }^{17}$ To this regard, in our study grade 3-4 D30 cytopenia was more common in heavily pretreated patients with low baseline ALC, which may indicate a weaker recipient immune system due to prior therapy, and a potentially easier product engraftment. ${ }^{18} \mathrm{~A}$

Table 2. Infection types (all grades included)

\begin{tabular}{lc} 
Total (N= 71) & Number (\%) \\
No isolated organism & $40(56)$ \\
$\quad$ 17 respiratory, 13 ENT, 3 skin, 4 GU, 2 GI, 1 sepsis) & \\
Viral, total & $17(24)$ \\
Herpetic (5 VZV, 3 HSV, 2 CMV, 1 HHV6) & $11(15)$ \\
Respiratory & $3(4)$ \\
Enteric & $1(1)$ \\
Parvovirus & $1(1)$ \\
Hepatitis B & $1(1)$ \\
Bacterial, total & $10(14)$ \\
Gram negative (2 UTI, 2 GI, 1 bacteremia) & $5(7)$ \\
Gram positive (3 GI, 2 skin) & $5(7)$ \\
Fungal, total & $4(6)$ \\
Yeast (skin) & $3(4)$ \\
Pneumocystis (pneumonia) & $1(1)$ \\
\hline
\end{tabular}

ENT: ear nose throat;VZV: varicella zoster virus; CMV: cytomegalovirus; HSV: herpes simplex virus; HHV6: human herpes virus 6; UTI: urinary tract infection; GI: gastrointestinal. 
trend for higher baseline ferritin levels in these patients also suggests a potential role for chronic inflammation in its etiology.

Consistent with prior studies in patients with $\mathrm{B}$-acute lymphoblastic leukemia (B-ALL) treated with anti-CD19 CAR T-cell therapy, we observed that viral infections, especially herpes zoster, were a later event, as compared to other infections. ${ }^{19,20}$ This is likely explained by the delayed recovery of $\mathrm{CD}^{+} \mathrm{T}$ cells, a well-established risk factor for the development of both common and opportunistic infections, which in this series occurred independently of age..$^{21}$ These data suggest that effective longterm monitoring and prophylaxis against opportunistic infections needs to be considered in a subset of patients receiving CAR T-cell therapy. Although the baseline characteristics of patients enrolled in the ZUMA-9 study mirrored those of patients treated in the real world setting, the subset of patients included in this analysis had an apparently higher incidence of grade $>3$ infections as compared to the 2-year follow-up of the ZUMA-1 trial ( $42 \%$ vs. $28 \%$ ). It is important to highlight that this may be due to differences in baseline characteristics and comorbid health conditions of the subset of patients selected for this single institution analysis, as compared to the previously reported multi-center results. ${ }^{2}$

While pre-conditioning IgG levels were not available in this study, and prior treatment with anti-CD20 monoclonal antibodies and/or chemotherapy may have affected their levels before CAR T-cell infusion, hypogammaglobulinemia was observed in a subset of patients early after axi-cel therapy. Similar to what was reported with the use of tisagenlecleucel, recovery of IgG to normal levels was observed in more than half the patients in this series..$^{22}$ In contrast to children where prophylactic IVIG is recommended with $\operatorname{IgG}<400 \mathrm{mg} / \mathrm{dL}$, in adults it is usually used in cases with concomitant frequent or severe infections ${ }^{23}$ Consistent with this, we did not observe significant differences in infections between patients receiving prophylactic IVIG or not $(P=0.10)$.

Finally, a strong and positive correlation between platelet count and CD56 cell count was observed in our study. NK cells are among the first hematopoietic cells that recover during bone marrow reconstitution, based on data from stem cell transplant recipients. ${ }^{24,25}$ The association observed here between platelet count and NK cell numbers might reflect the dynamics of bone marrow recovery, although a mechanistic relation may still be possible and is under evaluation at our institution.

In conclusion, our study suggests that patients with prolonged cytopenias after CAR T-cell therapy may be managed conservatively with supportive care. Importantly, our results suggest the potential need for antimicrobial prophylaxis against opportunistic infections because of delayed $\mathrm{CD}^{+}{ }^{+}$- -cell recovery following axicabtagene ciloleucel therapy in a subset of patients.

\section{Disclosure}

SSN reports honoraria and research support from Kite, a Gilead Company, Merck, Celgene, Allogene, and Unum Therapeutics; research support from Bristol-Myers Squibb, Poseida, Cellectis, Karus, and Acerta Pharma; and honoraria from Novartis, Pfizer, Precision Biosciences, Cell Medica, Calibr, Incyte, and Legend Biotech. FS reports honoraria from Celgene. LN reports honoraria from Celgene, Genentech, Gilead, Janssen, Juno, Novartis, Spectrum, TG Therapeutics and research support from Celgene, Genentech, Janssen, Karus Therapeutics, and Merck. NF reports honoraria from Celgene, Gilead Sciences, Pharmacyclics, Roche Pharma AG, research support from Celgene, Gilead Sciences, Pharmacyclics, and Roche Pharma AG.

\section{Contributions}

PS designed the study, analyzed data, and wrote the paper; $L N, J W, F H, N F, H J L, L E F, F S, S A, P K, V E M$ and EAH provided clinical care to patients and coauthored the paper; $Y C$, $S H, S A, A V, S A$, and SJ collected clinical data and co-authored the paper; $S N$ designed the study, analyzed the data, provided clinical care to patients, and wrote the paper.

\section{Acknowledgments}

This research is supported in part by the MD Anderson Cancer Center Support Grant P3O CA016672 and Kite Pharma. PS salary is supported by the Lymphoma Research Foundation Career Development Award. We thank Adrian Bot, John Rossi and Jenny Kim from Kite Pharma for data and manuscript review.

\section{References}

1. Neelapu SS, Locke FL, Bartlett NL, et al. Axicabtagene ciloleucel CAR T-cell therapy in refractory large B-cell lymphoma. $\mathrm{N}$ Engl J Med. 2017;377(26):2531-2544

2. Locke FL, Ghobadi A, Jacobson CA, et al. Long-term safety and activity of axicabtagene ciloleucel in refractory large B-cell lymphoma (ZUMA-1): a single-arm, multicentre, phase 1-2 trial. Lancet Oncol. 2019;20(1):31-42

3. Schuster SJ, Bishop MR, Tam CS, et al. Tisagenlecleucel in adult relapsed or refractory diffuse large B-cell l,ymphoma. N Engl J Med. 2019;380(1):45-56.

4. Strati P, Neelapu SS. Chimeric antigen receptor-engineered $\mathrm{T}$ cell therapy in lymphoma. Curr Oncol Rep. 2019;21(5):38.

5. Neelapu SS, Tummala S, Kebriaei P, et al. Chimeric antigen receptor T-cell therapy assessment and management of toxicities. Nat Rev Clin Oncol. 2018;15(1):47-62.

6. Lee DW, Santomasso BD, Locke FL, et al.
ASTCT consensus grading for cytokine release syndrome and neurologic toxicity associated with immune effector cells. Biol Blood Marrow Transplant. 2019;25(4):625638.

7. Fried S, Avigdor A, Bielorai B, et al. Early and late hematologic toxicity following CD19 CAR-T cells. Bone Marrow Transplant. 2019;54(10):1643-1650.

8. Raje N, Berdeja J, Lin Y, et al. Anti-BCMA CAR T-cell therapy bb2121 in relapsed or refractory multiple myeloma. N Engl J Med. 2019;380(18):1726-1737.

9. Abramson JS, Palomba ML, Gordon LI, et al. Pivotal safety and efficacy results from transcend NHL 001, a Multicenter Phase 1 Study of Lisocabtagene Maraleucel (liso-cel) in relapsed/refractory (R/R) large B cell lymphomas. Blood. 2019;134(Suppl 1):S241.

10. Shah NN, Highfill SL, Shalabi $\mathrm{H}$, et al. CD4/CD8 T-Cell selection affects chimeric antigen receptor (CAR) T-cell potency and toxicity: updated results from a phase I antiCD22 CAR T-cell trial. J Clin Oncol.
2020;38(17):1938-1950

11. Lee DW, Gardner R, Porter DL, et al. Current concepts in the diagnosis and management of cytokine release syndrome. Blood. 2014;124(2):188-195.

12. Cheson BD, Pfistner B, Juweid ME, et al. Revised response criteria for malignant lymphoma. J Clin Oncol. 2007;25(5):579-586.

13. Friedberg JW, Neuberg D, Stone RM, et al. Outcome in patients with myelodysplastic syndrome after autologous bone marrow transplantation for non-Hodgkin's lymphoma. J Clin Oncol. 1999;17(10):31283135 .

14. Cordeiro A, Bezerra ED, Hirayama AV, et al Late Events after treatment with CD19-targeted chimeric antigen receptor modified $\mathrm{T}$ cells. Biol Blood Marrow Transplant. 2020;26(1):26-33.

15. Strati P, Wierda W, Burger J, et al. Myelosuppression after frontline fludarabine, cyclophosphamide, and rituximab in patients with chronic lymphocytic leukemia: analysis of persistent and new- 
onset cytopenia. Cancer-Am Cancer Soc. 2013;119(21):3805-3811.

16. Tam CS, O'Brien S, Wierda W, et al. Longterm results of the fludarabine, cyclophosphamide, and rituximab regimen as initial therapy of chronic lymphocytic leukemia. Blood. 2008;112(4):975-980.

17. Brudno JN, Somerville RP, Shi V, et al. Allogeneic T cells that express an anti-CD19 chimeric antigen receptor induce remissions of B-cell malignancies that progress after allogeneic hematopoietic stem-cell transplantation without causing graft-versus-host disease. J Clin Oncol. 2016;34(10):11121121.

18. Bensinger W, Appelbaum F, Rowley S, et al. Factors that influence collection and engraftment of autologous peripheral-blood stem cells. J Clin Oncol. 1995:13(10):2547-2555.

19. Hill JA, Li D, Hay KA, et al. Infectious complications of CD19-targeted chimeric antigen receptor-modified T-cell immunotherapy. Blood. 2018;131(1):121-130.

20. Park JH, Romero FA, Taur Y, et al. Cytokine release syndrome grade as a predictive marker for infections in patients with relapsed or refractory B-cell acute lymphoblastic leukemia treated with chimeric antigen receptor $\mathrm{T}$ cells. Clin Infect Dis. 2018;67(4):533-540.

21. Jung AC, Paauw DS. Diagnosing HIV-related disease: using the CD4 count as a guide. J Gen Intern Med. 1998;13(2):131-136.

22. Schuster SJ, Svoboda J, Chong EA, et al. Chimeric antigen receptor $T$ cells in refractory B-cell lymphomas. $N$ Engl J Med.
2017:377(26):2545-2554

23. Brudno JN, Kochenderfer JN. Toxicities of chimeric antigen receptor T cells: recognition and management. Blood. 2016;127(26) :3321-3330.

24. Hattori N, Saito B, Sasaki Y, et al. Status of natural killer cell recovery in day 21 bone marrow after allogeneic hematopoietic stem cell transplantation predicts clinical outcome. Biol Blood Marrow Transplant. 2018;24(9):1841-1847.

25. Chang YJ, Zhao XY, Huang XJ. Effects of the NK cell recovery on outcomes of unmanipulated haploidentical blood and marrow transplantation for patients with hematologic malignancies. Biol Blood Marrow Transplant. 2008;14(3):323-334. 